International

Medical Society

http://imedicalsociety.org
2018

Vol. 11 No. 23

doi: $10.3823 / 2564$

\title{
Suicide in Children and Adolescents: a Review of Articles about this Topic
}

\section{Abstract}

Nowadays, depression in adolescents is understood to be a common, disabling and recurrent disease, with a high level of morbidity and mortality. Thus, it is an important public health problem. Suicide is the act of intentionally ending one's own life. It is related to biological, social, environmental factors and to the personal history, so, is a complex and multifactor phenomenon. The lack of research and literature with this population hinders the comprehension of the phenomenon and so the improvement of interventions in the field of prevention and care for survivors. This paper reviews on clinical and epidemiological aspects of suicide in Children, definitions and expressions of suicide among adolescents people are presented, identifying possible risk factors and prevention interventions are discussed.

\section{Introduction}

Suicide is among the leading causes of death worldwide, especially in adolescents and young adults [1]. Suicidal behavior includes the spectrum from thoughts or ideas that revolve around suicide or death (suicidal ideation) through fatal completion of suicide [2]. Suicide is the result of a deliberate self-inflicted act undertaken with the intent to end one's life begging an important public health problem for children and adolescents around the world [3].

Childhood and early adolescence are important periods for preventing the onset of suicidal behaviors [4]. The large spread of suicide suggests that educational programs and literature to parents or guardians should include information about the potential risks and potential consequences of the onset of the idea of suicide in children [5]. Screening for risk of suicide and suicidal behavior is an important and necessary first step toward suicide prevention in young people [6].

Bruna Magalhães Viana1, Fabiana Gouveia Guimarães ${ }^{1}$, Carlos César Messias Silva ${ }^{2}$

1 Residence in Pediatrics, Federal University of Cariri (UFCA), Barbalha, Brazil.

2 Faculty of Medicine, Federal University of Cariri (UFCA), Barbalha, Brazil.

Contact information:

Bruna Magalhães Viana.

Address: Federal University of Cariri, UFCA. Faculty of Medicine

Đ brunamagalhaespediatra@hotmail.com

Keywords

Depression; Adolescence; Clinical Features. 
Implementing effective screening programs involves targeting high-risk populations in favorable settings [7]. The National Action Alliance for Suicide Prevention (Action Alliance) developed 12 Aspirational Goals as a way of structuring a suicide prevention research agenda aimed at decreasing suicides in the U.S. by $40 \%$ over the next decade [8].

The proposed paradigm shift is that an effective suicide-screening instrument not only will detect imminent risk but can also identify youth with significant emotional distress warranting further mental health attention. A recent Canadian study revealed that $80 \%$ of youth who died by suicide visited a PC provider, an ED, or had an inpatient medical hospitalization within 3 months prior to their death [6]. The obvious clinical challenge is that these individuals do not walk into their doctor's office and say, "I want to kill myself"; rather, they frequently present with somatic complaints (e.g., headaches, stomachaches), and may not talk about their suicidal thoughts unless asked directly [10].

As there is no single clinical characterization of a suicidal or depressed individual (Kennebeck et al., 2015) diagnosis is time consuming to gather and requires a high degree of clinical training, practice and certification to produce acceptable results [11].

Suicide attempts and severe suicidal ideation have potentially serious consequences, including substantial psychological effects, increased risk of subsequent suicide attempt, and death [1]. Consequently, the prevention of suicidal behavior should be a national health priority, with the development of existing and new evidence-based, suicide preventive interventions [12].

\section{Epidemiology}

Worldwide, suicide is one of the three leading causes of death in young people. (Nock et al., 2013) little is known about the prevalence, correlates, or treatment of its immediate precursors, adolescent suicidal behaviors (ie, suicide ideation, plans, and attempts Suicide accounted for $7.3 \%$ of all deaths in the age group 15-19 years, after road traffic accidents (11.6\%), and preceding violence $(6.2 \%)$, respiratory tract infections (5.4\%), tuberculosis (4.8\%), and HIV (2.3\%) (Patton, 2009) According to the latest data from $\mathrm{WHO}$, figures are similar in 2014 [15]. Suicide is a major public health problem for children and adolescents worldwide [16].

Recently WHO estimated that over 800,000 people die from suicide every year send is the second leading cause of death between 10 and 24 years old [15] and there are at least 20 times more attempted suicides [15]. This increased suicide rate was at the expense of the male gender: from 5.6\% to $6.7 \%$ in males versus $1.6 \%$ to $1.4 \%$ in females [15].

While suicide is the eleventh leading cause of death among all ages in the United States, is the third leading cause of death among young people 12-19 [18], and the fifth leading cause of death among children.

An average of 16,375 youth ages 12 to 19 died each year from 1999 to 2006; 11\% of the severe suicides. The death rate from suicide among you the ages 15 to 24 year since the United States ranged from 9.7 to 10.3 per 100,000 people in the standard population during the years 1999 to 2007 [19]. Suicide rates doubled in the 15- to 19-year age group and tripled in the 10- to 14-year age group between the 1960s and the 1990s [2].

The reasons for this trend are unclear, although it is not simply because of increased reporting [20]. Possible explanations include increased rates of alcohol and drug abuse, depression, family and social disorganization, and access to firearms [2]. Moreover, one nationally representative survey in the US found that $12.1 \%$ of adolescents experience suicide ideation, $4 \%$ develops a suicide plan and $4.1 \%$ attempt suicide [13].

In Europe, the lifetime self-reported prevalence for similar age groups is 4.2\%. In England and Wales, between 2001 and 2010, there were 1,523 
suicide deaths among those aged 10-19 years [5]. In Brazil, the suicide rates for children ages 10 to 14 ranged from 0.4 to 0.6 per 100,000 during the period from 1980 to 2006 [21].

Suicide is the third leading cause of death among all children and adolescents in the United States, including those aged 10 to 19 years [22]. Adolescent suicide rates declined somewhat between the late 1980s and 2003, but increased between 2003 and 2004, and again between 2008 and 2009 [23]. After puberty, the rate of suicide among adolescents increases with increasing age [24].

Approximately one half of emotional and behavioral disorders that are well-defined risk factors for suicide have onset of symptoms by age 14 years [25]. Ideation of suicide is more common among young people than previously thought, with some recent estimates ranging $11-21 \%$ of the samples of non-clinical children and adolescents [26].

Therefore, it is important to understand the correlates of adolescent suicide to determine whether there are any suicide early warning signs [13]. Some authors consider that, under the age of 10 , children are not able to understand the true meaning of life and death, and the actual consequences of attempting against their lives, and thus are not capable to fully understand the meaning of the suicide practice itself [27].

Between 2003 and 2004, suicide rates increased among females aged 10 to 14 years (by 76 percent), females aged 15 to 19 years (by 32 percent), and males aged 15 to 19 years (by 9 percent) [23].

Female high school students are more likely than males to have a specific suicide plan (median of 16 versus 11 percent, with a range of 13 to 20 percent and 8 to 15 percent for females versus males, respectively) [28]. The most common suicide methods include shooting, hanging, poisoning, jumping from a high place, and running into traffic or other land transport [29]. In addition to the tragic deaths by suicide among youth, non-fatal suicide attempts and suicide-related ideation are leading causes of psychiatric hospitalization among children and adolescents, and constitute severe and often chronic impairment [30].

\section{Precipitating factors}

Depression was identified as the best predictor of suicidal ideation, according to literature [31]. Known risk factors include: an individual's age and gender (younger 15-24 year olds and older 65+ males are at higher risk of suicide, [32] an individual's psychiatric diagnosis, a history of suicide behavior, a family history of suicide [33] and personality type. gay or bisexual orientation, a history of physical or sexual abuse, and a previous suicide attempt [34].

Moreover social and environmental risk factors include the presence of firearms in the home, impaired parent-child relationship, living outside of the home (homeless or in a corrections facility or group home], difficulties in school, neither working nor attending school, social isolation, and presence of stressful life events such as legal or romantic difficulties or an argument with a parent [5].

The leading suicide method was hanging ( $\mathrm{n}=$ $6,35.3 \%)$, followed by shooting ( $n=3,17.6 \%$ ), and running against a moving train ( $n=3,17.6 \%)$. Other methods used were drowning $(n=2)$, carbon monoxide (CO] poisoning ( $n=2)$, and jumping from a high place $(n=1)$. No suicide using poisoning by medication or pesticides/herbicides and cutting/stabbing was reported. Studies shown that the use of violent methods is associated with younger ages and represents acts of impulsivity [35]. This can be explained by the fact that victims are not yet aware of the extent of the outcome, as the methods may be more efficient than they may have thought [36].

Females who commit suicide are more likely to have experienced sexual abuse [37]. However, the rate of suicidal ideation and suicide attempts are greater in girls than boys. Female high school students are more likely than males to have a specific suicide plan and one nationally representative sur- 
vey in the US found that the lifetime prevalence of suicide attempt was greater in adolescent females than males $6 \%$ versus $2 \%$ [13]. As an example, public health data from the United States showed that the rate of suicide deaths among males aged 10 to 19 years was 7 per 100,000, and for females was 2 per 100,000 [38].

Risk factors associated with female suicide are less well known but prior research carried out in the Americas has suggested that partner violence and adolescent pregnancy are risk factors [5].

Hanging/suffocation is the most common and lethal method of suicide especially for males, followed by jumping from a height, especially for females [5]. Girls tend to choose less lethal means such as overdose or carbon monoxide poisoning, whereas boys tend to choose firearms and hanging [39].

Some psychological traits can increase risk, such as impulsive aggression in which a child may have a tendency to react aggressively. Environmental factors such as psychosocial stressors, poverty, and "non-intact" families may contribute to hopelessness. Many youth have acute stressors that include interpersonal conflict, loss, and problems with school [40].

Protective factors such as strong relationships with adults, academic success, or religious beliefs can modify these risk factors and reduce risk for suicidal behaviors - but even these are not always sufficiently protective [9]. There is, however, the need to go beyond simple associations and focus on integrative causal mechanisms [31].

\section{Conclusion}

Despite the importance of the social and health aspects regarding suicide, there is a paucity of research related to suicide in children [17]. Suicide attempt and suicidal behaviours in adolescents are known predictors of mental health problems and future suicidal behaviours throughout their life- course, which calls for early preventive measures [31]. Suicide can be prevented. The results point to the need to increase our understanding of the dramatic rise in suicidal behaviors during childhood/ adolescence and of the causal pathways linking these behaviors to child-adolescent mental disorders [42].

Much effort in psychiatric medicine has gone into identifying risk factors for suicide, in order to implement actionable strategies for clinical prediction. To this purpose, adequate training is critical to ensure that pediatricians are prepared to provide effective assessment, prevention and intervention for suicidal behavior [42]. During routine care visits, pediatricians should be skilled to recognize risk factors for adolescent suicide in order to intervene appropriately [5]. In addition, multidisciplinary teams should be created to ensure the most effective response to the health and development of children/ adolescents. Key research gaps must be addressed to identify specific strategies and programs with greatest suicide prevention potential. Upstream interventions delivered through social systems in childhood and early adolescence have the potential for reducing population-level suicide rates [43].

It is time for all youth in medical settings to be screened for suicide risk, just as they are routinely screened for hypertension, fever, and falls risk. In the future, other intervention strategies and settings may emerge as promising, such as interventions aimed at modifying adolescent norms for behavior through social media networks or that provide "option-rich" alternatives that can be adapted to address individual needs (e.g., individuals choose modules to suit specific emotional, behavioral, or life-context needs]. We cannot rely solely on depression screens or non-validated instruments to identify young people at risk for suicide. We as researchers need to create and test developmentally sound tools for healthcare providers to use [44].

Lastly, we must hold ourselves, as clinicians and researchers, accountable for lowering the youth sui- 
cide rate within the next decade. Every healthcare provider can have an impact [45].

\section{References}

1. Borges G, Nock MK, Haro Abad JM, et al. Twelve-month prevalence of and risk factors for suicide attempts in the World Health Organization World Mental Health Surveys. J Clin Psychiatry. 2010; 71(12):1617-1628.

2. Kennebeck, SMD, Bonin,,Lindberg,DM, Brent, MDD, Solomon MD. Suicidal behavior in children and adolescents: Epidemiology and risk factors. Uptodate. http://www.uptodate.com/contents/ suicidal-behavior-in-children-and-adolescents-epidemiologyand-risk-factors. Published 2015. Accessed April 9, 2015.

3. Cummins N, Scherer S, Krajewski J, Schnieder S, Epps J, Quatieri TF. A review of depression and suicide risk assessment using speech analysis. Speech Commun. 2015; 71(Supplement C):1049.

4. Wyman PA. Developmental Approach to Prevent Adolescent Suicides: Research Pathways to Effective Upstream Preventive Interventions. Am J Prev Med. 2014; 47(3 0 2):S251-S256.

5. Ferrara $P$, Ianniello F, Cutrona $C$, et al. A focus on recent cases of suicides among Italian children and adolescents and a review of literature. Ital J Pediatr. 2014; 40:69.

6. Horowitz LM, Bridge JA, Pao M, Boudreaux ED. Screening youth for suicide risk in medical settings: time to ask questions. Am J Prev Med. 2014; 47(3 Suppl 2):S170-5.

7. Pena JB, Caine ED. Screening as an approach for adolescent suicide prevention. Suicide Life Threat Behav. 2006; 36(6):614637

8. Claassen CA, Pearson JL, Khodyakov D, et al. Reducing the burden of suicide in the U.S.: the aspirational research goals of the National Action Alliance for Suicide Prevention Research Prioritization Task Force. Am J Prev Med. 2014; 47(3):309-314.

9. Horowitz LM, Bridge JA, Pao M, Boudreaux ED. Screening youth for suicide risk in medical settings: time to ask questions. Am J Prev Med. 2014; 47(3 Suppl 2):S170-5

10. Rhodes $A E$, Khan S, Boyle MH, et al. Sex differences in suicides among children and youth: the potential impact of help-seeking behaviour. Can J Psychiatry. 2013; 58(5):274-282.

11. Mundt JC, Snyder PJ, Cannizzaro MS, Chappie K, Geralts DS. Voice acoustic measures of depression severity and treatment response collected via interactive voice response (IVR] technology. J Neurolinguistics. 2007; 20(1):50-64.
12. Wasserman D, Rihmer Z, Rujescu D, et al. The European Psychiatric Association (EPA] guidance on suicide treatment and prevention. Eur Psychiatry. 2012; 27(2):129-141.

13. Nock MK, Green JG, Hwang I, et al. Prevalence, correlates, and treatment of lifetime suicidal behavior among adolescents: results from the National Comorbidity Survey Replication Adolescent Supplement. JAMA psychiatry. 2013; 70(3):300-310.

14. Patton GC, Coffey C, Sawyer SM, Viner RM, Haller DM, Bose K, Vos T, Ferguson J, Mathers CD. Global patterns of mortality in young people: a systematic analysis of population health data. Lancet. 2009 Sep 12; 374(9693):881-92.

15. WHO. Preventing suicide: a global imperative. WHO. http:// www.who.int/mental health/suicide-prevention/world report 2014/en/. Accessed March 24, 2015.

16. Shain BN. Suicide and suicide attempts in adolescents. Pediatrics. 2007; 120(3):669-676.

17. Mendes R, Santos S, Taveira F, Dinis-Oliveira RJ, Santos A, Magalhães T. Child Suicide in the North of Portugal. J Forensic Sci. 2015; 60(2):471-475.

18. Minino A. Mortality among teenagers aged $12-19$ years: United States, 1999-2006. NCHS Data Brief. 2010; (37):1-8.

19. Martinez MS. Correlates of Suicide-Related Behaviors among Children Ages Six to Twelve. 2013.

20. Brent DA, Perper JA, Allman CJ. Alcohol, firearms, and suicide among youth. Temporal trends in Allegheny County, Pennsylvania, 1960 to 1983. JAMA. 1987; 257(24):3369-3372.

21. Lovisi GM, Santos SA, Legay L, Abelha L, Valencia E. Análise epidemiológica do suicídio no Brasil entre 1980 e 2006. Rev Bras Psiquiatr. 2009; 31(suppl 2):S86-S93.

22. Kochanek KD, Kirmeyer SE, Martin JA, Strobino DM, Guyer B. Annual summary of vital statistics: 2009. Pediatrics. 2012; 129(2):338-348

23. Murphy SL, Xu J, Kochanek KD. Deaths: final data for 2010. Natl Vital Stat Reports From Centers Dis Control Prev Natl Cent Heal Stat Natl Vital Stat Syst. 2013; 61(4):1-117.

24. Anderson RN. Deaths: leading causes for 2000. Natl Vital Stat Rep. 2002; 50(16):1-85

25. O'Connell ME, Boat T, Warner KE, eds. Preventing Mental, Emotional, and Behavioral Disorders Among Young People Progress and Possibilities. Washington (DC): National Academies Press (US]; 2009

26. Eaton DK, Kann L, Kinchen S, et al. Youth risk behavior surveillance--United States, 2007. MMWR Surveill Summ. 2008; 57(4):1-131

27. Arslan M, Akcan R, Hilal A, Batuk H, Cekin N. Suicide among children and adolescents: data from Cukurova, Turkey. Child Psychiatry Hum Dev. 2007; 38(4):271-277.

28. White A, Hingson R. The burden of alcohol use: excessive alcohol consumption and related consequences among college students. Alcohol Res. 2013; 35(2):201-218. 
29. Mendes R, Santos S, Taveira F, Dinis-Oliveira RJ, Santos A, Magalhães T. Child Suicide in the North of Portugal. J Forensic Sci. 2015; 60(2):471-475.

30. Asarnow JR, Baraff LJ, Berk M, et al. Pediatric emergency department suicidal patients: two-site evaluation of suicide ideators, single attempters, and repeat attempters. J Am Acad Child Adolesc Psychiatry. 2008; 47(8):958-966.

31. Barzilay S, Feldman D, Snir A, et al. The interpersonal theory of suicide and adolescent suicidal behavior. J Affect Disord. 2015; 183:68-74.

32. Frontmatter. In: The International Handbook of Suicide and Attempted Suicide. John Wiley \& Sons, Ltd; 2008.

33. Brendel, R.W., Wei, M., Lagomasino, I.T., Perlis, R.H., Stern T. Massachusetts General Hospital Handbook of General Hospital Psychiatry. 6th ed. Saint Louis; 2010.

34. Shain BN. Suicide and suicide attempts in adolescents. Pediatrics. 2007; 120(3):669-676.

35. Dumais $A$, Lesage $A D$, Lalovic $A$, et al. Is violent method of suicide a behavioral marker of lifetime aggression? Am J Psychiatry. 2005; 162(7):1375-1378.

36. Nock MK, Kessler RC. Prevalence of and risk factors for suicide attempts versus suicide gestures: analysis of the National Comorbidity Survey. J Abnorm Psychol. 2006; 115(3):616-623.

37. Quinlan-Davidson M, Sanhueza A, Espinosa I, Escamilla-Cejudo JA, Maddaleno M. Suicide among young people in the Americas. J Adolesc Health. 2014; 54(3):262-268.

38. Cash SJ, Bridge JA. Epidemiology of youth suicide and suicidal behavior. Curr Opin Pediatr. 2009; 21(5):613-619.

39. Bloch DS. Adolescent suicide as a public health threat. J Child Adolesc Psychiatr Nurs. 1999; 12(1):26-38.

40. Karch DL, Logan J, McDaniel DD, Floyd CF, Vagi KJ. Precipitating circumstances of suicide among youth aged 10-17 years by sex: data from the National Violent Death Reporting System, 16 states, 2005-2008. J Adolesc Health. 2013; 53(1 Suppl):S51-3.

41. Barzilay S, Feldman D, Snir A, et al. The interpersonal theory of suicide and adolescent suicidal behavior. J Affect Disord. 2015; 183:68-74

42. Litwiller BJ, Brausch AM. Cyber bullying and physical bullying in adolescent suicide: the role of violent behavior and substance use. J Youth Adolesc. 2013; 42(5):675-684.
43. Wyman PA. Developmental Approach to Prevent Adolescent Suicides: Research Pathways to Effective Upstream Preventive Interventions. Am J Prev Med. 2014; 47(3 0 2):S251-S256.

44. Pisani AR, Wyman PA, Petrova M, et al. Emotion Regulation Difficulties, Youth--Adult Relationships, and Suicide Attempts Among High School Students in Underserved Communities. J Youth Adolesc. 2013; 42(6):807-820.

45. Horowitz LM, Bridge JA, Pao M, Boudreaux ED. Screening youth for suicide risk in medical settings: time to ask questions. Am J Prev Med. 2014; 47(3 Suppl 2):S170-5.
Publish in International Archives of Medicine

International Archives of Medicine is an open access journal publishing articles encompassing all aspects of medical science and clinical practice. IAM is considered a megajournal with independent sections on all areas of medicine. IAM is a really international journal with authors and board members from all around the world. The journal is widely indexed and classified Q2 in category Medicine. 